\title{
'A study to assess the effectiveness of planned teaching programme on knowledge of Type I osteoporosis and its prevention among menopause women in selected PHC at Bijapur'
}

\author{
${ }^{1}$ Mr.Shalmon S chopade, ${ }^{2}$ Mr.Shashikumar Jawadagi, ${ }^{3}$ Mr.Basheer Ahemad J \\ Sikandar \\ ${ }^{I}$ MSc Nursing, Dept of Medical Surgical Nursing, BLDEAS Shri.B.M Patil Institute of Nursing Sciences, \\ RGUHS Bangalore, India. \\ ${ }^{2}$ MSc Nursing,Dept of Medical Surgical Nursing, BLDEAS Shri.B.M Patil Institute of Nursing Sciences, RGUHS \\ Bangalore, India. \\ ${ }^{3}$ MSc Nursing,Dept of Medical Surgical Nursing, BLDEAS Shri.B.M Patil Institute of Nursing Sciences, RGUHS \\ Bangalore, India.
}

\begin{abstract}
:
Background: Osteoporosis is a common age-related disorder manifested clinically by skeletal fractures. Women lose bone density faster in menopause when estrogen level decreases.

Objectives: To assess the level of knowledge on type I osteoporosis and its prevention among menopause women.
\end{abstract}

Methods: A pre-experimental design was used to find the effectiveness of PTP on type I osteoporosis among 100 menopause women between the age group of 40 - 70 years were included with convenient sampling technique from Bijapur District, Karnataka. Data was collected by using demographic proforma and questionnaires through interview method.

Result: The area wise distribution of pre test knowledge scores on type I osteoporosis and its prevention. The respondents had inadequate knowledge scores in all the areas. Whereas post test knowledge scores were adequate in the area of General information with mean $\pm S D$ as $(92.4 \%, 4.62 \pm 5.2)$ and Causes and risk factors $(78 \%, 3.12 \pm 0.58)$. And moderately adequate knowledge scores in the area of Prevention $(71.67 \%, 4.30 \pm$ 1.05), Clinical manifestation and diagnosis $(70.50 \%, 4.23 \pm 0.96)$, Management $(59.50 \%, 3.57 \pm 1.29)$ respectively. The computed ' $t$ ' values (25.65) between the mean of pre test and post test was more than the critical 't' value at a level of significance of $0.05 \%$. The result test shows that the improvement of mean knowledge score of post test when compared with lesser value of pre test.

Conclusion: Hence its emerging need of the day to educate all the menopause women about osteoporosis and its prevention to gain good life.

\section{Introduction:}

Musculoskeletal system forms the pivotal part of the human body. The skeleton holds the body upright and serves as protective armor for the body's internal organs. ${ }^{1}$ Bones are made of complex, constantly changing, living tissue. They are able to grow and heal, and are also susceptible to changes in diet, body chemistry, and exercise levels. These are the changes that can lead to osteoporosis. ${ }^{2}$ For women bone formation is fastest in the first few years after menopause. Osteoporosis mainly affects women, but also affects men. Osteoporosis will develop when bone resorption occurs too quickly or when replacement occurs too slowly. ${ }^{3}$ Osteoporosis represents an increasingly serious health and economic problem in India and around the world. Many individuals, experience pain, disability, and diminished quality of life as a result of having this condition. ${ }^{4}$ Although exact numbers are not available, but based on available data 300 million Indians may be affected at a younger age than in the West. Recently published data have clearly demonstrated widespread vitamin D deficiency across India, at all ages and in both sexes, particularly in the urban areas. Poor sunlight exposure, skin pigmentation and a vitamin D-deficient diet are some obvious causes for this finding. Indians have low BMD as compared to the western Caucasians. ${ }^{5}$ According to WHO, The annual incidence rate of osteoporotic fracture in women is greater than the incidence rate of heart attack, stroke and breast cancer. Osteoporosis will put bigger burden to the health care system as treatment is expensive. ${ }^{6}$ One out of 8 male and one out of 3 female in India suffers from osteoporosis, making India one of the largest affected countries in the world. One in two Indian women above the age of 45 suffers from osteoporosis. So this is a huge problem in India. ${ }^{7}$ Failure to identify at-risk patients, to educate them, and to implement preventive measures may lead to tragic consequences. Medical care includes calcium, vitamin D, antiresorptive agents and estrogen receptor modulator. Surgical care includes vertebroplasty and kyphoplasty. These public health measures are recommended for the 
population at large as they are efficacious, safe and cost-effective. The peak bone mass of the population can be increased significantly by appropriate and timely intervention in children. Pharmacological interventions are expensive and should therefore be targeted to only those at high risk of fractures. ${ }^{4}$

Section B: Description Of Pre And Post Test Knowledge Scores On Type I Osteoporosis And Its Prevention Among Menopause Women.

\begin{tabular}{|l|l|l|}
\hline Level of knowledge & Frequency & Percentage \\
\hline Adequate knowledge & 00 & 00 \\
\hline Moderately adequate knowledge & 12 & 12 \\
\hline Inadequate knowledge & 88 & 88 \\
\hline Total & 100 & 100 \\
\hline
\end{tabular}

Above table shows that majority (88\%) of respondents had inadequate knowledge and only (12\%) of respondents had moderately adequate knowledge scores. Whereas none of the respondent had adequate knowledge scores on type I osteoporosis and its prevention.

\section{Title Of The Study}

'A study to assess the effectiveness of planned teaching programme on knowledge of Type I osteoporosis and its prevention among menopause women in selected PHC at Bijapur'

\section{Objectives}

1. To assess the level of knowledge on type I osteoporosis and its prevention among menopause women.

2. To determines the effectiveness of planned teaching programme on knowledge of type I osteoporosis and its prevention among menopause women.

3. To find out the association between level of knowledge and selected demographic variable of menopause women.

\section{Hypothesis:}

H1: There is significant difference between the pre-test and post-test knowledge scores of menopause women regarding Type I osteoporosis and its prevention

H2: There is significant association between the pre-test knowledge scores of menopause women with their selected demographic variables.

\section{Methodology:}

A pre-experimental design was used to find the effectiveness of planned teaching programme on type I osteoporosis and its prevention among one hundred menopause women were included between the age group of 40 - 70 years with Non probability convenient sampling technique from Bableshawar PHC, Bijapur District, Karnataka. Data was collected by using demographic proforma and questionnaires through interview method

\section{Results}

\section{Section A: Description Of The Demographic Characteristics Of Menopause Women.}

Majority (68\%) of respondents were in the age group of 51 to 60 years, Majority ( $45 \%)$ of respondents had primary education, Majority $(62 \%)$ of respondents were doing moderate work, Majority $(72 \%)$ of respondents were Hindus, Majority (78\%) of respondents were enjoying mixed diet (veg and non veg), Majority $(45 \%)$ of respondents had menopause in age of 46 to 50 years and highest (67\%) of respondents had 10,000 to 20,0000 monthly family income.

Section B: Description Of Pre And Post Test Knowledge Scores On Type I Osteoporosis And Its Prevention Among Menopause Women.

\begin{tabular}{|l|l|l|}
\hline Level of knowledge & Frequency & $\mathbf{1 0 0}$ \\
\hline Adequate knowledge & 00 & Percentage \\
\hline Moderately adequate knowledge & 12 & 00 \\
\hline Inadequate knowledge & 88 & 12 \\
\hline Total & 100 & 88 \\
\hline
\end{tabular}

Above table shows that majority (88\%) of respondents had inadequate knowledge and only (12\%) of respondents had moderately adequate knowledge scores. Whereas none of the respondent had adequate knowledge scores on type I osteoporosis and its prevention. 
'A study to assess the effectiveness of planned teaching programme on knowledge of ....

Distribution Of Post Test Knowledge Scores Of Menopause Women Regarding Type I Osteoporosis And Its Prevention

\begin{tabular}{|l|l|l|}
\hline \multicolumn{2}{|c|}{$\mathbf{N}=\mathbf{1 0 0}$} \\
\hline Level of knowledge & Frequency & Percentage \\
\hline Adequate knowledge & 26 & 26 \\
\hline Moderately adequate knowledge & 44 & 44 \\
\hline Inadequate knowledge & 30 & 30 \\
\hline Total & 100 & 100 \\
\hline
\end{tabular}

Above table shows that majority (44\%) of respondents had moderately adequate knowledge scores and $(30 \%)$ of respondents had inadequate knowledge scores. Whereas $(26 \%)$ of the respondent had adequate knowledge scores after post test on type I osteoporosis and its prevention.

Section C: Description Of Pre And Post Test Knowledge Scores On Different Aspects Of Type I Osteoporosis And Its Prevention Among Menopause Women.

\begin{tabular}{|c|c|c|c|c|c|c|}
\hline \multirow[t]{2}{*}{ Sl.no } & \multirow[t]{2}{*}{ Area of knowledge } & \multirow[t]{2}{*}{ No. of items } & \multicolumn{3}{|c|}{ Pre test knowledge } & \multirow{2}{*}{$\begin{array}{l}\text { Level of } \\
\text { knowledge }\end{array}$} \\
\hline & & & Mean & SD & Mean \% & \\
\hline 1 & General information & 4 & 0.80 & 0.49 & 45 & IAK \\
\hline 2 & $\begin{array}{l}\text { Causes and risk factors of type I } \\
\text { osteoporosis }\end{array}$ & 6 & 1.18 & 0.49 & 39.33 & IAK \\
\hline 3 & Clinical manifestation and diagnosis & 5 & $\mathbf{0 . 7 2}$ & 0.80 & 36 & IAK \\
\hline 4 & Management of type I osteoporosis & 6 & 1.10 & 0.47 & 27.50 & IAK \\
\hline \multirow[t]{2}{*}{5} & Prevention of type I osteoporosis & 9 & 1.15 & 0.48 & 38.33 & IAK \\
\hline & Total & 30 & 5.95 & 2.73 & 37.23 & \\
\hline
\end{tabular}

Analysis revealed that the area wise distribution of pre test knowledge scores of the respondents on type I osteoporosis and its prevention. The respondents had inadequate knowledge scores in all the areas as fallows General information with mean $\pm \mathrm{SD}$ as $(45 \%, 1.80 \pm 0.49)$, Causes and risk factors of type I osteoporosis $(38.33 \%, 1.15 \pm 0.48)$, Clinical manifestation and diagnosis $(36 \%, 0.72 \pm 0.80)$, Management of type I osteoporosis $(27.50 \%, 1.10 \pm 0.47)$, Prevention of type I osteoporosis $(39.23 \%, 1.18 \pm 0.49)$. These findings reveal that the menopause women had inadequate knowledge regarding type I osteoporosis and its prevention. Hence its emerging need of the day to educate all the menopause women about osteoporosis and its prevention.

Distribution Of Area-Wise Post Test Knowledge Scores With Their Mean, Sd And Mean\%.

\begin{tabular}{|l|l|l|l|l|l|l|}
\hline Sl.no & Area of knowledge & No. of items & \multicolumn{2}{l|}{$\begin{array}{l}\text { Post test knowledge } \\
\text { Level } \\
\text { knowledge }\end{array}$} \\
\cline { 3 - 7 } & & & Mean & SD & Mean \% \\
\hline 1 & General information & 4 & 4.62 & 5.2 & 92.4 & AKS \\
\hline 2 & $\begin{array}{l}\text { Causes and risk factors of type I } \\
\text { osteoporosis }\end{array}$ & 6 & 4.30 & 1.50 & 71.67 & AKS \\
\hline 3 & Clinical manifestation and diagnosis & 5 & 4.23 & 0.96 & 70.50 & MAKS \\
\hline 4 & Management of type I osteoporosis & 6 & 3.57 & 1.29 & 59.50 & MAKS \\
\hline 5 & Prevention of type I osteoporosis & 9 & 3.12 & 0.58 & 78 & MAKS \\
\hline & Total & 30 & 19.8 & 9.1 & 74.4 & \\
\hline
\end{tabular}

Analysis revealed that the area wise distribution of post test knowledge scores of the respondents on type I osteoporosis and its prevention. The respondents had adequate knowledge score in the area of General information with mean $\pm \mathrm{SD}$ as $(92.4 \%, 4.62 \pm 5.2)$ and Causes and risk factors of type I osteoporosis $(78 \%$, $3.12 \pm 0.58)$. Whereas moderately adequate knowledge scores in the area of Prevention of type I osteoporosis with mean $\pm \mathrm{SD}(71.67 \%, 4.30 \pm 1.05)$, Clinical manifestation and diagnosis $(70.50 \%, 4.23 \pm 0.96)$, Management of type I osteoporosis $(59.50 \%, 3.57 \pm 1.29)$ respectively.

Section D: Evaluating Effectiveness Of Planned Teaching Programme On Knowledge Of Type I Osteoporosis And Its Prevention Among Menopause Women.

\begin{tabular}{|c|c|c|c|c|c|c|c|c|}
\hline \multirow{2}{*}{$\begin{array}{l}\text { Sl.n } \\
\text { o }\end{array}$} & \multirow[t]{2}{*}{ Area of knowledge } & \multicolumn{2}{|c|}{ Pre test knowledge } & \multicolumn{2}{|c|}{ Post test knowledge } & \multicolumn{2}{|c|}{ Enhancement } & \multirow[t]{2}{*}{ 't' test } \\
\hline & & Mean & SD & Mean & SD & Mean & SD & \\
\hline 1 & General information & 0.80 & 0.49 & 4.62 & 5.20 & 3.82 & 4.47 & $\mathrm{t}=4.75$ \\
\hline 2 & $\begin{array}{l}\text { Causes and risk factors of } \\
\text { type I osteoporosis }\end{array}$ & 1.18 & 0.49 & 4.30 & 1.50 & 3.12 & 1.01 & $\mathrm{t}=3.77$ \\
\hline 3 & $\begin{array}{l}\text { Clinical manifestation and } \\
\text { diagnosis }\end{array}$ & 0.72 & 0.80 & 4.23 & 0.96 & 3.51 & 0.16 & $\mathrm{t}=9.74$ \\
\hline
\end{tabular}


'A study to assess the effectiveness of planned teaching programme on knowledge of ....

\begin{tabular}{|l|l|l|l|l|l|l|l|l|}
\hline 4 & $\begin{array}{l}\text { Management of type I } \\
\text { osteoporosis }\end{array}$ & 1.10 & 0.47 & 3.57 & 1.29 & 2.47 & 0.82 & $\mathrm{t}=3.62$ \\
\hline 5 & $\begin{array}{l}\text { Prevention of type I } \\
\text { osteoporosis }\end{array}$ & 1.15 & 0.48 & 3.12 & 0.58 & 1.97 & $\mathbf{0 . 1 0}$ & $\mathrm{t}=3.77$ \\
\hline & Total & 5.95 & 2.73 & 19.8 & 9.1 & 11.38 & $\mathbf{6 . 5 6}$ & $\mathrm{t}=25.65$ \\
\hline
\end{tabular}

The above table shows that the results of application of ' $t$ ' test (two tail test) to area wise pre test and post test knowledge scores. The computed ' $t$ ' values (25.65) between the mean of pre test and post test was more than the critical ' $t$ ' value obtained from ' $t$ ' table at a level of significance of $0.05 \%$. the result of ' $t$ ' test shows that the improvement of mean knowledge score of post test when compared with lesser value of pre test were not by chance but due to the gain in knowledge because of planned teaching programme was effective at a level of significance of $0.05 \%$.

\section{Hypothesis Testing}

In order to evaluate the significant difference between the pre test and post test level of knowledge scores among menopause women regarding Type I osteoporosis and its prevention the fallowing research hypothesis was formulated

H1: There is significant difference between the pre-test and post-test knowledge scores of menopause women regarding Type I osteoporosis and its prevention.

After using the statistical measures it was evident that there is significant difference between pre test and post test knowledge scores of menopause women regarding Type I osteoporosis and its prevention. Hence research hypothesis was accepted.

Section E: Association between pre test knowledge scores with selected demographic variables of menopause women.

The number of respondents who were above and below the median were identified and grouped according to their demographic characteristics like Age, Educational status, Religion, Nature of work, Family Income, Food habit and Age of menopause.

To test the association between the pre test knowledge score with demographic variables, the following research hypothesis was formulated:

H2: There is significant association between the pre-test knowledge scores of menopause women with their selected demographic variables.

Table 12: Chi-square values showing the association between pre-test knowledge score of menopause women with their selected demographic variables

$\mathbf{N}=\mathbf{1 0 0}$

\begin{tabular}{|c|c|c|c|c|c|}
\hline Sl. No. & Demographic variables & $\chi^{2}$ value & 'p' value & df & Significance \\
\hline 1. & Age & 10.74 & 0.005 & 3 & $\mathrm{~S}$ \\
\hline 2. & Educational status & 11.11 & 0.004 & 2 & $\mathrm{~S}$ \\
\hline 3. & Religion & 0.149 & 0.7 & 1 & N S \\
\hline 4. & Nature of work & 5.021 & 0.285 & 4 & NS \\
\hline 5. & Family income & 6.86 & 0.076 & 3 & N S \\
\hline 6. & Food habit & 8.56 & 0.014 & 2 & $\mathrm{~S}$ \\
\hline 7. & Age of menopause & 9.89 & 0.02 & 3 & $\mathrm{~S}$ \\
\hline
\end{tabular}

$\mathrm{S}=$ Significant; NS $=$ Not significant

The above data shows the association between pre test knowledge scores of the respondents with selected demographic variables. The association between knowledge score and age $\left(\chi^{2}=10.74, \mathrm{P}=0.005\right)$, educational status $\left(\chi^{2}=11.11, \mathrm{P}=0.004\right)$, food habits $\left(\chi^{2}=8.56, \mathrm{P}=0.014\right)$, and age of menopause $\left(\chi^{2}=9.89 \mathrm{P}\right.$ $=0.02)$ where highly significant. However the association between knowledge score and other demographic variables like religion, nature of work and family income were not significant at 0.05 level

The above table shows that the calculated chi-square value was more than the table value. Hence there was a significant association between pre-test knowledge score and selected demographic variables of menopause women. Therefore, the research hypothesis is accepted.

Distribution Of Post Test Knowledge Scores Of Menopause Women Regarding Type I Osteoporosis And Its Prevention

\begin{tabular}{|l|l|l|}
\hline \multicolumn{2}{|l}{} & $\mathbf{N}=\mathbf{1 0 0}$ \\
\hline Level of knowledge & Frequency & Percentage \\
\hline Adequate knowledge & 26 & 26 \\
\hline Moderately adequate knowledge & 44 & 44 \\
\hline Inadequate knowledge & 30 & 30 \\
\hline Total & 100 & 100 \\
\hline
\end{tabular}


Above table shows that majority (44\%) of respondents had moderately adequate knowledge scores and $(30 \%)$ of respondents had inadequate knowledge scores. Whereas $(26 \%)$ of the respondent had adequate knowledge scores

\section{Discussion}

As silent and preventable in nature, postmenopausal osteoporosis awareness should be raised among young women prior to an irreversible period of declining bone mass. We therefore decided to assess the intercorrelation of knowledge, attitude and osteoporosis preventive behaviors in women around the age of peak bone mass.

In the present study majority (88\%) of respondents had inadequate knowledge and only (12\%) of respondents had moderately adequate knowledge scores. Whereas none of the respondent had adequate knowledge scores in pre test on type I osteoporosis and its prevention. Whereas post test knowledge scores, $(44 \%)$ of respondents had moderately adequate knowledge scores and $(30 \%)$ of respondents had inadequate knowledge scores. Whereas (26\%) of the respondent had adequate knowledge scores after post test on type I osteoporosis and its prevention.

The similar study conducted on Risk status related to knowledge of osteoporosis in older women with 211 women age 60 in a southwestern state. Using a two-tailed Pearson correlation, there was no significant correlation between being at risk and a person's knowledge of osteoporosis prior to or after the educational program. Using a one-tailed t-test, there was a significant increase in knowledge from pre-test to post-test. ${ }^{8}$

\section{Evaluating Effectiveness Of Planned Teaching Programme On Knowledge Of Type I Osteoporosis And Its Prevention Among Menopause Women.}

The above table shows that the results of application of ' $t$ ' test (two tail test) to area wise pre test and post test knowledge scores. The computed ' $t$ ' values (25.65) between the mean of pre test and post test was more than the critical ' $t$ ' value obtained from ' $t$ ' table at a level of significance of $0.05 \%$. the result of ' $t$ ' test shows that the improvement of mean knowledge score of post test when compared with lesser value of pre test were not by chance but due to the gain in knowledge because of planned teaching programme was effective at a level of significance of $0.05 \%$.

A study was conducted to assess the level of teaching strategies of life style modification among women with postmenopausal osteoporosis. The study consist of 50 samples a structured questionnaire was used. The study concluded that administering a teaching material for the patient is an effective method of health education the study emphasized the need for developing more teaching material for the patient with osteoporosis for improving their knowledge and there by lead healthy life. ${ }^{9}$

\section{Conclusion}

Nurses are primarily involved in giving comprehensive care to the patients suffering from osteoporosis. Hence it is required that nurses possess a thorough knowledge of the disorders. The findings drawn from the study is of a vital concern to health team including nursing services, nursing education, nursing administration, and nursing research. There is need for developing health education package with regard to different aspects of osteoporosis, in order to improve the knowledge of osteoporotic patient and mass health education campaign should be organized regularly by health team to provide education on osteoporosis. Assessing the stress and improving the quality of life in patients with osteoporosis as it is a very subjective experience, rather than the belief in simply treating the patient with drugs.

\section{References}

[1]. The skeletal system (Internet).Available from: http://www.encyclopedia.com/doc/1G2-3437000032.html.

[2]. Osteoporosis (Internet).Available from: http://en.wikipedia.org/wiki/Osteoporosis

[3]. Lawrence G. Raisz. Pathogenesis of osteoporosis: concepts, conflicts, and prospects J Clin Invest. Dec 1, 2005; 115(12): 33183325. (Internet).Available from: http://www.ncbi.nlm.nih.gov/pmc/articles/PMC1297264/

[4]. Dinesh K Dhanwal, Elaine M Dennison, Nick C Harvey, and Cyrus Cooper Epidemiology of hip fracture: Worldwide geographic variation Indian J Orthop. 2011 Jan-Mar; 45(1): 15-22. (Internet).Available from: http://www.pubfacts.com/author/Dinesh+K+Dhanwal
Malhotra N, Mithal A. Osteoporosis in Indians. Indian J Med Res.2008 Mar;127(3):263-8. (Internet).Available from: http://www.ncbi.nlm.nih.gov/pubmed/18497441

[6]. Mithal A, Bansal B, Kyer CS, Ebeling P. The Asia-Pacific Regional Audit-Epidemiology, Costs, and Burden of Osteoporosis in India 2013: A report of International Osteoporosis Foundation.Indian J Endocrinol Metab. 2014 Jul;18(4):449-54. (Internet).Available from: http://www.ncbi.nlm.nih.gov/pubmed/25143898

[7]. World Health Organization - International osteoporosis foundation Journal of osteoporosis, Page151-183, 1990.

[8]. Curry LC, Hogstel MO.Risk status related to knowledge of osteoporosis in older women. J Women Aging. 2001;13(2):71-83. (Internet).Available from: http://www.ncbi.nlm.nih.gov/pubmed/?term=pre+and+post+test+knowledge+of+osteoporosis + in + menopause+women

[9]. Teaching strategies of life style modification among women with postmenopausal osteoporosis. (Internet).Available from: https://www.nursing.arizona.edu/Library/Mar_JH.pdf 